\title{
Forecasting Strategies for Haboobs: An Underreported Weather Phenomenon
}

\author{
Mark J. Dempsey \\ The Graduate Center, CUNY, Earth and Environmental Sciences, 365 Fifth Avenue, New York, NY 10016, USA \\ Correspondence should be addressed to Mark J. Dempsey; mdempsey@gc.cuny.edu
}

Received 23 June 2014; Accepted 5 August 2014; Published 18 August 2014

Academic Editor: Sven-Erik Gryning

Copyright (C) 2014 Mark J. Dempsey. This is an open access article distributed under the Creative Commons Attribution License, which permits unrestricted use, distribution, and reproduction in any medium, provided the original work is properly cited.

\begin{abstract}
On June 5, 2013, Lubbock Texas is hit by a haboob at 10:30 pm. The storm is categorized as a wind event by television media and the dust component goes unreported. This event is used as a case study to evaluate the usefulness of the polarimetric variables differential reflectivity (ZDR) and correlation coefficient (CC) in identifying the storm as a haboob. Photographic evidence of the haboob is collected and correlated to NEXRAD signatures of base reflectivity and velocity from the Lubbock TX NEXRAD station (KLBB). NEXRAD level III products ZDR and CC are also obtained. The storm presents with gust front features to the north and east of the station. Low values returned from CC indicate nonmeteorological content. ZDR representations weakly indicate the presence of gust fronts to the east, with a stronger signal to the north. As no visual evidence of the northern gust front is available, the ZDR data are inconclusive. The correlation of low CC values to the visual representation of the haboob is an indicator that CC in combination with the NEXRAD base reflectivity and velocity products may be used to test wind events for the presence of sand, dust, and dirt and therefore exhibit predictive qualities.
\end{abstract}

\section{Introduction}

The word haboob is taken from the Arabic habūb meaning "blasting" or "drafting," and according to Sutton 1925 [1] habb is "wind" or "to blow." It is a name given by the Sudanese to African dust storms and more recently a name given to dust storms found in the American West and Southwest. Vasiloff et al. 2009 refer to them as downburst storms, Pauley et al. 1996 [2] as dust storms, Riley 1931 [3] as dry squalls, and Pye and Tsoar, 2012 [4], as squalls, and the National Weather Service in its notes about the 1930s Black Sunday Dust storm [5] refers to them as black blizzards, black dusters, black rollers, northers, and dirt storms. These storms have played an important role in our lives both historically and in the present. During the 1930s, the western parts of Texas and Oklahoma were known as "the Dust Bowl." Dust storms pounded the region destroying crops, livestock, and many lives and properties. Today, in the same region, as in the 1930s, severe drought is in evidence and although planting practices have improved since then so that the soil is somewhat more stable, dust storms still impact the region.
This paper will focus upon these storms: American haboobs, and in particular a single haboob that occurred on June 5, 2013. By the time the storm had hit Lubbock, TX, at 10:30 pm local time, it had become a severe wind event. Local television stations were warning the population about the severity of the oncoming winds, recommending that they take shelter in the innermost part of their home-advice also given to people in advance of an oncoming tornado. What the television reporters never mentioned was the fact that this storm was a haboob. Storm reports were coming in from upwind of the storm with information on wind speed and direction and there were occasional mentions of poor visibility but no mention of the dust component (Fox News Lubbock, Texas, can be heard by clicking the following link: https://www.youtube.com/watch?v=og7RuVkgNAo). This begs several questions that this paper will attempt to address: why should the reporting of dust in this or any storm be important? Why was the dust component of this storm unreported? Are haboobs generally underreported? Are there methods available to us that can alert forecasters to the presence of dust in these powerful storms? 
With the help of the National Weather Service's NextGeneration Radar Network, severe convective storms can be observed as they develop. As recently as 2010, the NEXRAD network was upgraded and became capable of using polarimetric variables for weather observation. This paper proposes to take a look at NEXRAD data for the Lubbock, TX, storm and to examine the NEXRAD data products: reflectivity $(Z)$, differential reflectivity (ZDR) base velocity, and correlation coefficient (cc or $\rho h v)$. The results presented here suggest that the use of polarimetric radar is a useful tool to identify dust in a severe wind event, thereby being useful as a haboob forecasting tool.

The following section will give a short background on haboob research. Section 3 will describe the Lubbock, TX, haboob from the authors' eyewitness account. Section 4 will discuss methodology and data, focusing on the NEXRAD network and the use of polarimetric data products to identify the dust component of a haboob. Section 5 will discuss through the use of photographs and figures of reflectivity, base velocity, and correlation coefficient that the storm was indeed a haboob and that discernment in advance through the aid of radar polarimetric variable data might have made this storm predictable not only as a high wind event, but also as a haboob. Section 6-the conclusion-will shed light on the questions posed above.

\section{Background}

There are few haboob case studies (Sutton 1925 [1]; Idso et al. 1972 [6]; Pauley et al. 1996 [2]; Vasiloff and Howard 2009 [7]; Solomos et al. 2012 [8]; Vukovic et al. 2014 [9]) and while all have in common the transport of great amounts of sand, dirt, and dust and the diminishment of visibility as an outflow/gust front passes, each highlights different aspects of the storm they describe. John Riley 1931 [3] of the Dallas Texas weather bureau describes a 1931 sandstorm as deriving from dry atmospheric conditions which give rise to dry squalls characterized by "a sudden shift of the wind through $90^{\circ}$ or more generally from the southwesterly to a northwesterly direction." Solomos et al. 2012 [8] state that increased dust emissions and recirculation of the elevated particles inside the head of the density current result in the formation of a moving "dust wall." In their article called "An American haboob," Idso et al. 1972 [6] relate that the passage of a haboob may be accompanied by fluctuations in pressure (mentioned also by Sutton 1925 [1]), but "there is invariably a fall in temperature and a rise in relative humidity." Vasiloff and Howard 2009 [7], in their investigation of downburst storms in Phoenix AZ, state that downbursts frequently produce strong outflows that entrain dust and reduce visibility to dangerous levels. Pauley et al. 1996 [2] describe a dust storm in California's San Joaquin Valley that satellite imagery reveals as having very few clouds related to the storm. Wakimoto 2001 [10], in his treatment of convective outflows, describes these downdrafts as typically subsaturated owing to the effects of the flow warming adiabatically as it descends, while Srivastava 1984 [11] theorizes that the intensification of the downdraft is accomplished when there is more moisture in the lower atmosphere as the parcel of air subsides. These facts are relevant to haboobs that produce little or no rain or hail. Although the treatise of Sutton 1925 [1] is not a case study per se but of an early climatological examination of haboobs in the Sudan, his description of haboobs of Khartoum is quite comprehensive, observing multiple storms over a three-year period and cataloguing their wind and storm direction, their source, and their season.

\section{A Case Study: June 5, 2013}

A discussion of our direct contact with the storm is as follows. Early in the afternoon of June 5, 2013, the author and the Nimbus Storms Research Lab chase team (Nadia Elfarnawani, Aline Gjelaj, Joey Krastel, and Meredith Robson), while driving north through New Mexico, noticed that our radar was picking up pulse thunderstorms which were developing up in the Santa Fe National Forest. The radar was viewable through an iPhone app called Radarscope, which ingests level III NEXRAD data, maps each variable, and displays it on the phone screen. By 1 pm two storms had distinguished themselves on the radar and were rolling out of the forest descending onto the plateau. By 3:30 pm these storms had intensified as they approached Las Vegas, NM. Migrating east/southeast by $5: 19$ a gust front feature had appeared in the base reflectivity of the National Weather Service (NWS) Weather Surveillance Radar-1988 Doppler located at Cannon Air force Base, Clovis NM (WSR-88D; KFDX). The front was advancing ahead of the thunderstorm. As the storm hit Tucumcari, NM, the weather report announced limited visibility due to haze. As it headed south across Quay County we had just come off the Llano Estacado (palisaded plain) and were entering the valley from the south. We drove several miles on route 209 toward the storm and then stopped. The gust front was clearly visible and tinged with the red Quay County soil. We positioned ourselves close to the advancing storm and then allowed it to chase us back south. By $6: 19$ the haboob was intensifying as it cleared the cap rock (the Llano Estacado). We drove south to the Town of Melrose where we got out for gas and to take more photos. We left Melrose and drove toward Clovis, the storm following close behind. From Clovis we travelled down route 84 to Muleshoe, TX, then on to Littlefield, and finally we arrived in Lubbock at 10:30 pm just as the Haboob was about to roar through. The first rain was blood red. Then the rain cleared as it began to mix with mothball-sized hail. We could barely see as we drove and so pulled off the highway and into a mall parking lot. Joey Krastel videoed the mothball size hail (http://www.youtube.com/watch?v=Sd2EXeTh8UU). The power went out in the mall complex so we went into a bar to wait out the storm. When the power came back on we listened to the television report extensive flooding throughout the city. The map in Figure 1 below shows the route followed from 4:30 pm to 10:30 pm.

\section{Methodologies}

A methodology was determined by the need to execute two tasks. The first was to assess the storm that was viewed on June 5, 2013, and determine that what was seen was, in fact, a 


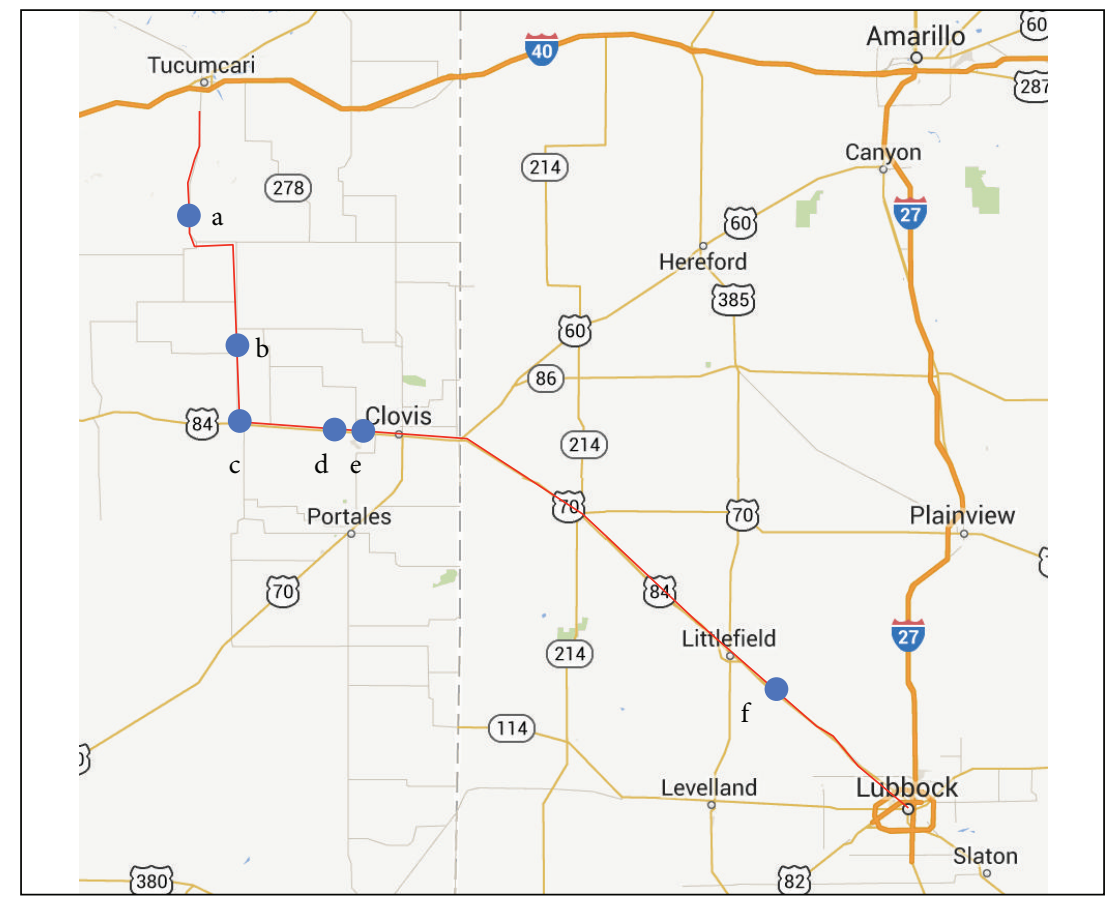

FIgURE 1: Map of route. The map shows the route that the author took going from just south of Tucumcari NM to Lubbock TX. The letters $\mathrm{a}-\mathrm{f}$ refer to Figure 2. They are the location where photos of the haboob were taken.

haboob. Given the success of the first task, the second task was to evaluate the NEXRAD radar data products to see whether or not a signature or combination of signatures might be interpreted as identifying the storm as a haboob.

The author encountered the storm at about $4: 30 \mathrm{pm}$ in the afternoon coming north off the Llano Estacado in New Mexico into the Quay Valley. We were struck by the approach of what appeared to be a great churning red wave of sand heading south along the valley toward us. We got in front of the storm and proceeded to let it chase us, taking photos periodically until we came to Lubbock TX later that evening. Figure 2 visually chronicles the progress of the haboob over time.

4.1. NEXRAD and Polarimetry. The Radar Operations Center (ROC) is a part of the National Weather Service and is the home of the Next-Generation Radar or NEXRAD. It was established in 1988 in Norman, OK. The ROC sets up the Weather Surveillance Radar-1988 Doppler or WSR88D network, which consists of 160 operational, S-band (10 cm wavelength) NEXRAD weather radar systems. In 2010 the ROC began work on upgrading all of the radars to polarimetric capability. Now, besides the ability to record the 0th, first, and second moments, the radars are now capable of emitting both horizontal and vertical radar waves. This enhancement produces the new variables: differential reflectivity, differential phase, and correlation coefficient. Since this paper discusses the haboob in terms of a propagating gust front and its representation via reflectivity, differential reflectivity, base velocity, and correlation coefficient, a short description of each variable is set here.
Reflectivity $(Z)$ is the 0th moment, the backscattered signal return of the emitted beam. The radar emits a horizontal beam. This means that if the scatterers in a range volume are positioned horizontally, then the reflectivity will be higher than if they are not. For example, large oblate raindrops produce a higher signal return than the small round raindrops of mist. Klingle and Smith 1987 [12] describe the reflectivity signature for a gust front as a "thin line."

Differential reflectivity is a measure of the log of the ratio of the horizontal to vertical power returns in a pulse volume, which can also be thought of as the log of the ratio of the horizontal reflectivity to vertical reflectivity in linear units, not $\mathrm{dBZ}$ units. Its values range from -7.9 to +7.9 in units of decibels $(\mathrm{dB})$ :

$$
\mathrm{ZDR}=10 \log _{10}\left[\frac{Z_{h}}{Z_{v}}\right]
$$

If the scatterers are round then the ZDR will be zero because the return from both the vertical and horizontal scatterers will be similar. Negative ZDR is infrequent although when encountered it is usually the result of the alignment of ice needles in the presence of lightning. Non meteorological clutter such as birds or insects can also return negative values. A positive ZDR indicates that the range volume contains scatterers aligned horizontally.

Specific to gust fronts or density currents are a change in the direction of the wind with the passage of the front. As discussed by Klingle and Smith 1987 [12], this can be seen in the Doppler velocity as a pattern of linear convergence along the radial. The first moment or radial velocity is the record 


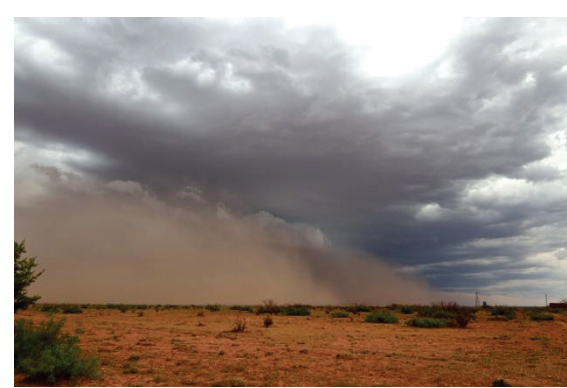

$6: 47 \mathrm{pm}$ local

(a)

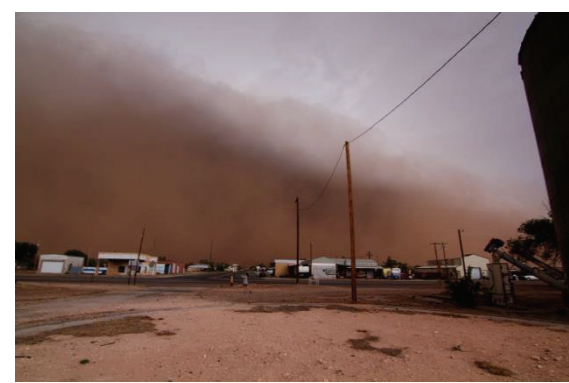

$7: 48$ pm local

(c)

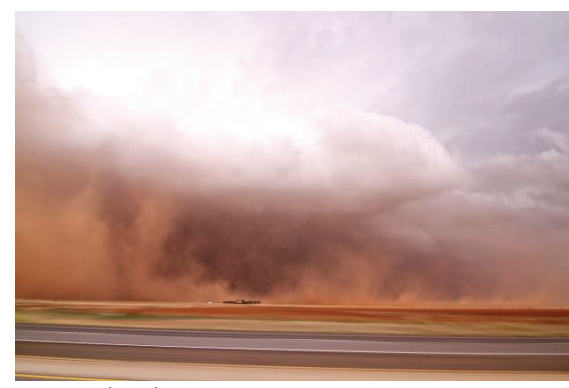

8:01 pm local

(e)

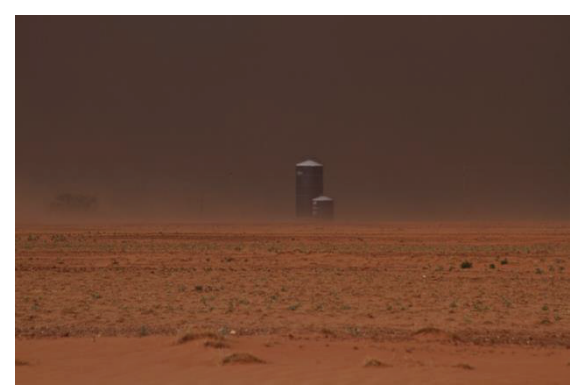

$7: 37 \mathrm{pm}$ local

(b)

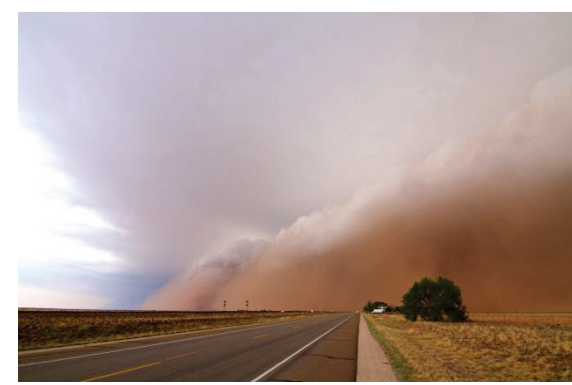

$7: 58 \mathrm{pm}$ local

(d)

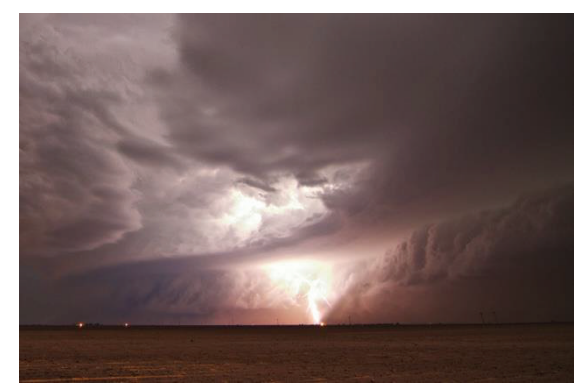

9:48 pm local

(f)

Figure 2: Photos of Haboob from (a) Route 209, Quay Valley, NM. (b) Llano Estacado, North of Melrose, NM. (c) Melrose, NM. (d) Between Melrose and Clovis, West View. (e) Between Melrose and Clovis, East View. (f) South of Littlefield. Locations may be seen on map in Figure 1.

of the general movement toward or away from the Doppler radar by the scatterers located in the range volume.

Correlation coefficient (CC) speaks to the homogeneity of the scatterers in a range volume. It is a measure of how similarly the horizontal and vertical pulses are behaving within a pulse volume. If the phase angle and magnitude of both the horizontal and vertical pulses behave similarly from time step to time step in the same range volume, $\mathrm{CC}$ is 1 or very close to 1 . Divergent magnitudes or phase angles return a lower CC. CC can therefore be used to distinguish meteorological hydrometeors from nonmeteorological scatterers such as birds, insects, wind farms, smoke plumes, and chaff. Values for these scatterers tend to be low.

\section{Discussion}

Establishing the presence of a gust front as the cause of the June 5 haboob requires both the NEXRAD reflectivity and velocity signatures. Once established, the polarimetric variables may be read in this light and an attempt to discern a signature specific to haboobs can be made. Klingle and Smith 1987 [12] describe the reflectivity signature for a gust front as a "thin line." In the case of the June 5 haboob, the Lubbock NEXRAD station (KLBB) base reflectivity (Figure 3(a)) presents this signature at $8: 25 \mathrm{pm}$ local time (CDT). There is a thin line echo in advance of the thunderstorm. There is another thin line running east to west to the north of Lubbock also.

The June 5 Doppler velocity shows linear convergence in the radial along the same thin line regions depicted by the reflectivity. This can be seen also at 8:25 pm local time (CDT) in Figure 3(b). The presence of the gust front being established, patterns in the polarimetric variables can be sought.

There is evidence in the ZDR (Figure 3(c)) of both the northern gust front and the gust front advancing before the thunderstorm. But although both gust fronts are evident, their signatures are slightly different from one another. The 


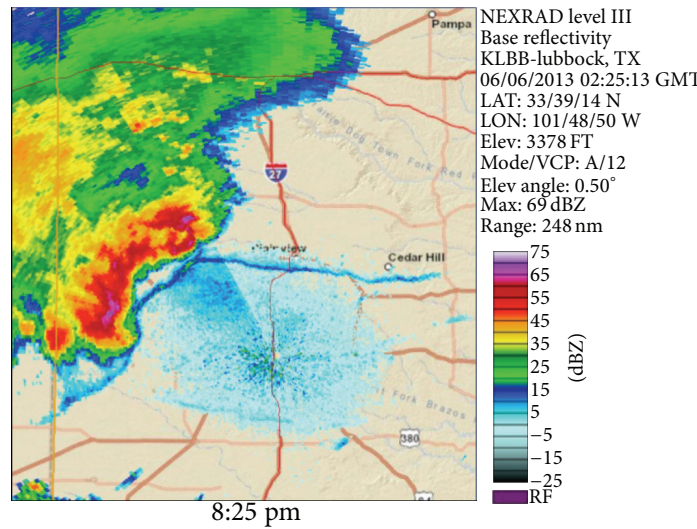

(a)

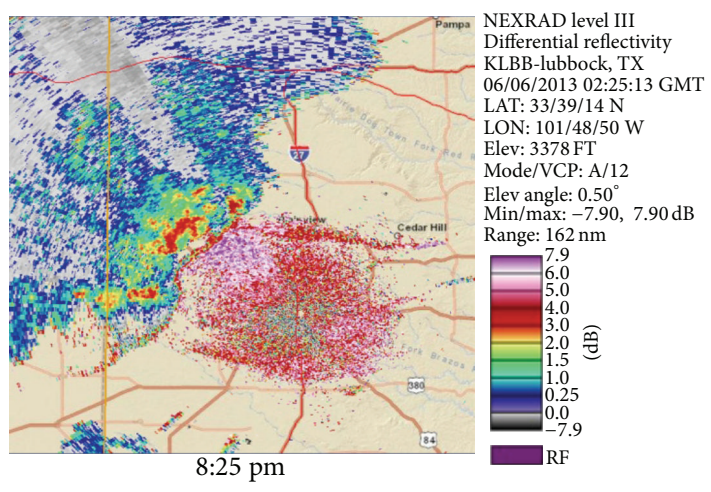

(c)

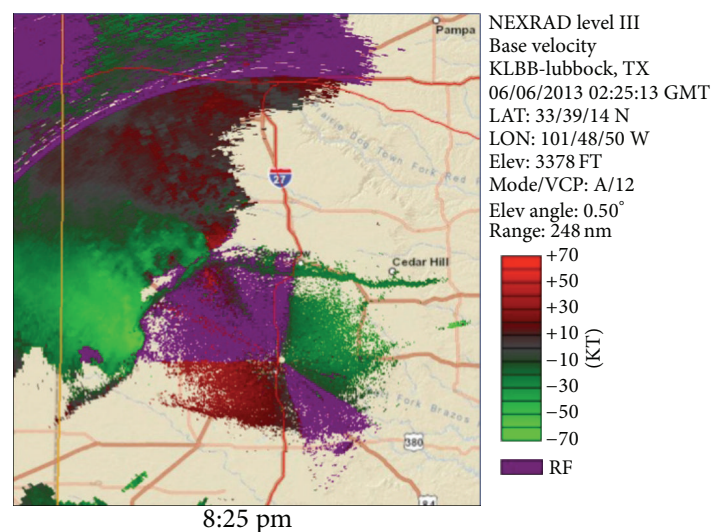

(b)

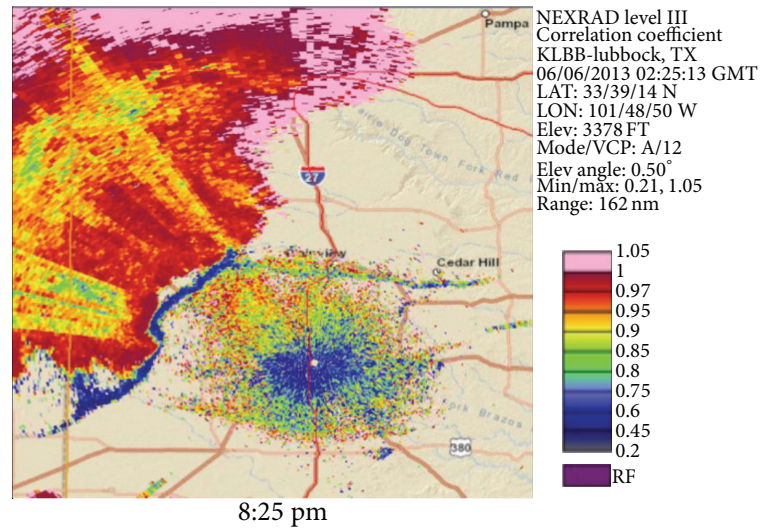

(d)

FIgURE 3: NEXRAD representation of Haboob, June 5, 2013. (a) Base reflectivity. (b) Base velocity. (c) Differential reflectivity (ZDR). (d) Correlation coefficient.

northern gust front shows high values more or less evenly distributed whereas the gust front advancing before the thunderstorm, which we witnessed as being comprised of sand, dust, and dirt, shows mixed values. It is unclear at this point if the ZDR signal indicates anything specific to the haboob. The only possible statement one might make is that the northern gust front may be with little or no sand, dust, or dirt and therefore simply a gust front. But this needs to be verified through field experience.

The correlation coefficient (Figure 3(d)) shows a clear low signal-approximately 0.5 -on the approaching gust front preceding the thunderstorm. This clear low signal can also be seen on the northern gust front; although the line is much fainter it is still present as a very thin blue line.

There is no way to verify that the northern gust front was a haboob because no one was present to witness it. The gust front in advance of the thunderstorm, though, was definitely a haboob and the nonmeteorological signature found in the correlation coefficient is significant.

\section{Conclusion}

The importance of forecasting and reporting haboobs lies in the fact that the invasion of dust and particulate matter into the environment causes serious health risks that might be mitigated with enough advanced forecasting. Couple this with the haboob's capacity to reduce visibility; making transportation extremely dangerous, forecasting these storms becomes imperative. While the June 5, 2013, Lubbock, TX, haboob was a single unreported incident, it is not difficult to make the leap that there have been other storms that have been similarly unreported. Whether this is a widespread problem or not is unclear. Nevertheless, the use of the correlation coefficient in the light of both reflectivity and base velocity can help forecasters visually identify the gust fronts responsible for haboobs and their transport of nonmeteorological materials. This idea opens up many possibilities in regard to future research, in particular, the possibility of developing an algorithm that identifies gust fronts as carriers of sand, dust, or dirt. With identification comes the possibility of identifying historical events and thereby developing a haboob climatology. There is also the possibility that various particulates may have specific ranges in the CC spectrum. It is this author's wish that this case study might provide information for the improvement and development of the numerical modeling of dust transport for use in operational forecasting. 


\section{Conflict of Interests}

The author declares that there is no conflict of interests regarding the publication of this paper.

\section{Acknowledgments}

The author would like to thank his program advisors in the past and present, Haydee Salmun of Hunter College, Andrea Molod of University of Maryland, and Jimmy Booth of City College, CUNY, for their extraordinary support in developing this research. The author would also like to thank the Nimbus Storm Research Lab: Nadia Elfarnawani, Aline Gjelaj, Joey Krastel, and Meredith Robson for all their support and their passion for the storm chase.

\section{References}

[1] L. J. Sutton, "Haboobs," Quarterly Journal of the Royal Meteorological Society, vol. 51, pp. 25-30, 1925.

[2] P. M. Pauley, M. Patricia, N. L. Baker, and E. H. Barker, "An observational study of the "Interstate 5" dust storm case," Bulletin of the American Meteorological Society, vol. 77, no. 4, pp. 693-720, 1996.

[3] J. A. Riley, "Sandstorms in Texas," Monthly Weather Review, vol. 59, pp. 30-31, 1931.

[4] K. Pye and H. Tsoar, Aeolian Sand and Sand Dunes, Springer, Amsterdam, The Netherlands, 2012.

[5] National Weather Service: Norman Oklahoma, “The Black Sunday Dust Storm of 14 April 1935," http://www.srh.noaa.gov/oun/ ?n=events-19350414.

[6] S. B. Idso, R. S. Ingram, and J. M. Pritchard, "An American Haboob," Bulletin of the American Meteorological Society, vol. 53, pp. 930-935, 1972.

[7] S. V. Vasiloff and K. W. Howard, "Investigation of a severe downburst storm near Phoenix, Arizona, as seen by a mobile Doppler Radar and the KIWA WSR-88D," Weather and Forecasting, vol. 24, no. 3, pp. 856-867, 2009.

[8] S. Solomos, G. Kallos, E. Mavromatidis, and J. Kushta, "Density currents as a desert dust mobilization mechanism," Atmospheric Chemistry and Physics, vol. 12, no. 22, pp. 11199-11211, 2012.

[9] A. Vukovic, M. Vujadinovic, G. Pejanovic et al., "Numerical simulation of "an American haboob'”, Atmospheric Chemistry and Physics, vol. 14, pp. 3211-3230, 2014.

[10] R. M. Wakimoto, "Convectively driven high wind events," Meteorological Monographs, vol. 28, pp. 255-298, 2001.

[11] R. C. Srivastava, A Simple Model of the Evaporatively Driven Downdraft: Application to Microburst Downdraft, University of Chicago, Department of the Geophysical Sciences, 1984.

[12] D. L. Klingle and D. R. Smith, "Gust front characteristics as detected by Doppler radar," Monthly Weather Review, vol. 115, no. 5, pp. 905-918, 1987. 

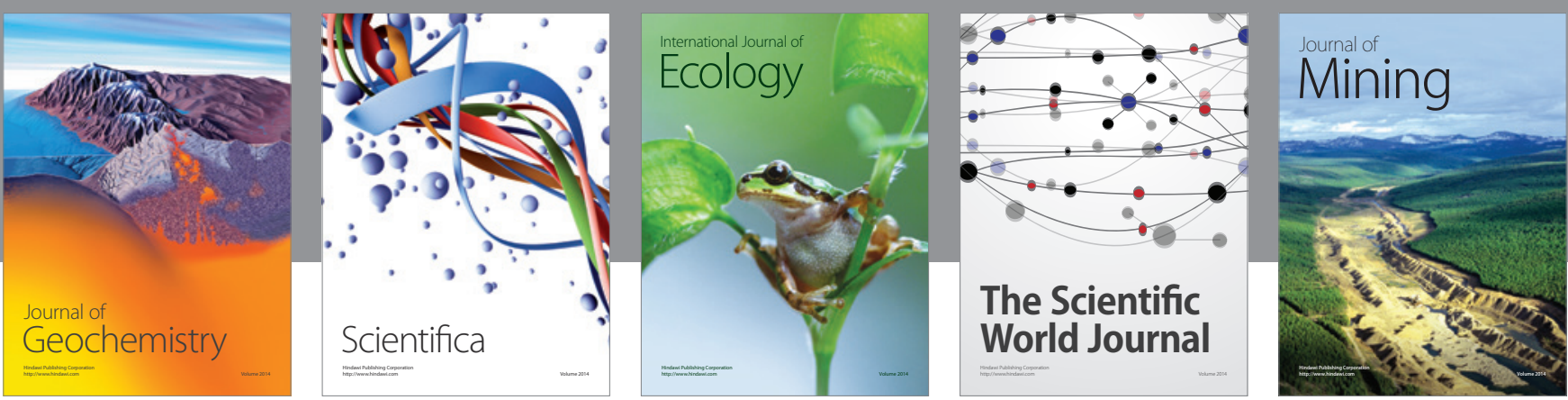

The Scientific World Journal
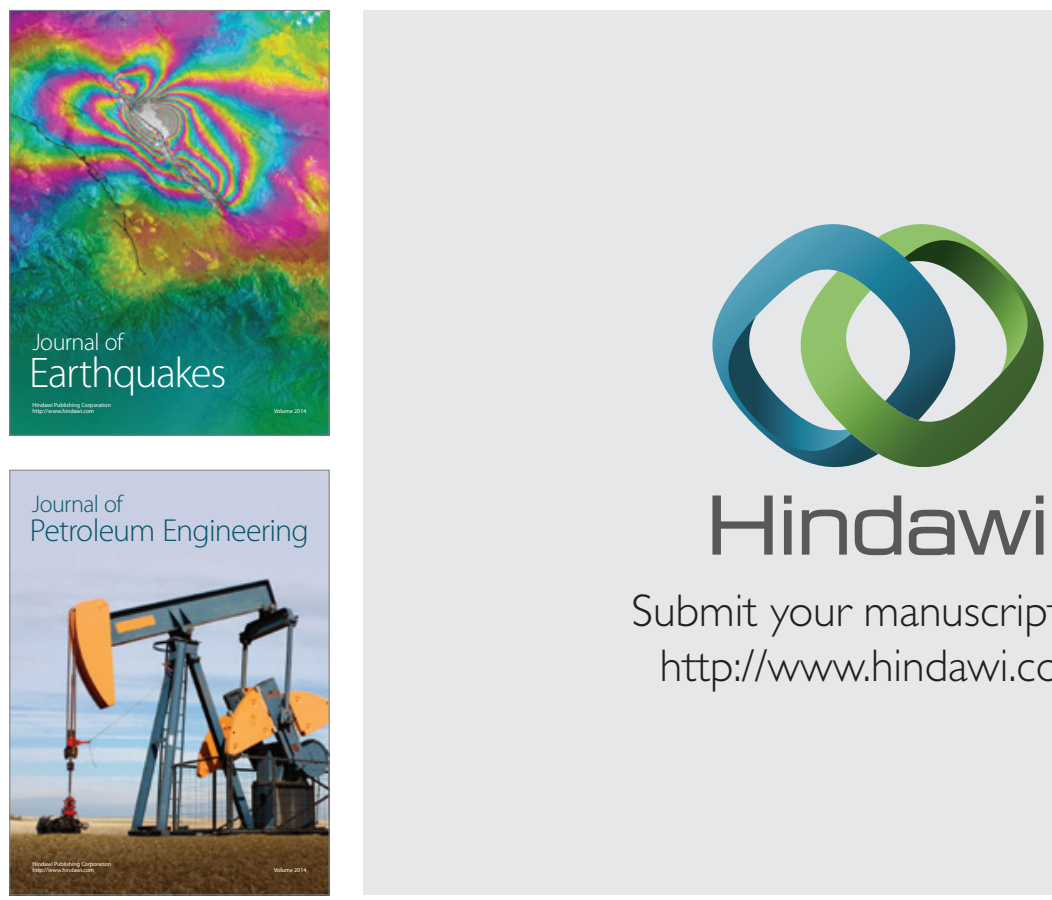

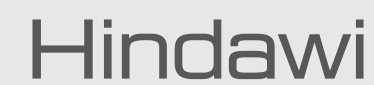

Submit your manuscripts at

http://www.hindawi.com
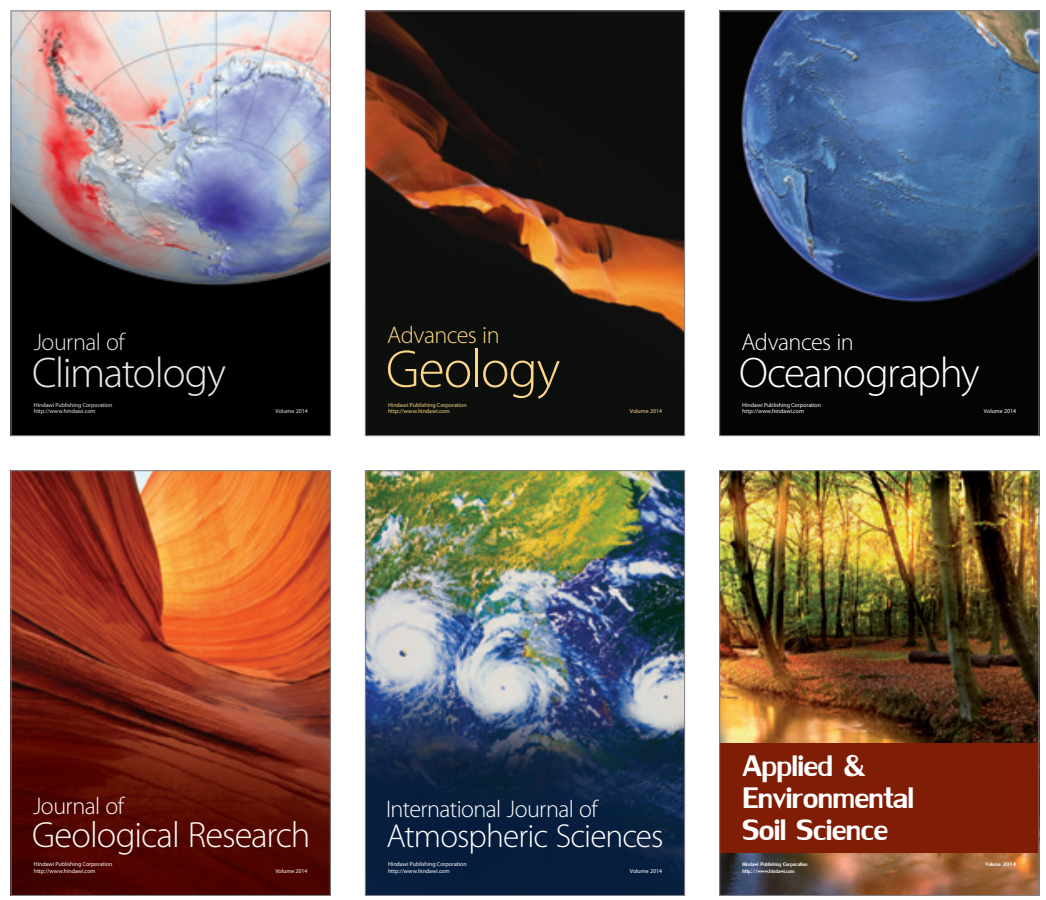
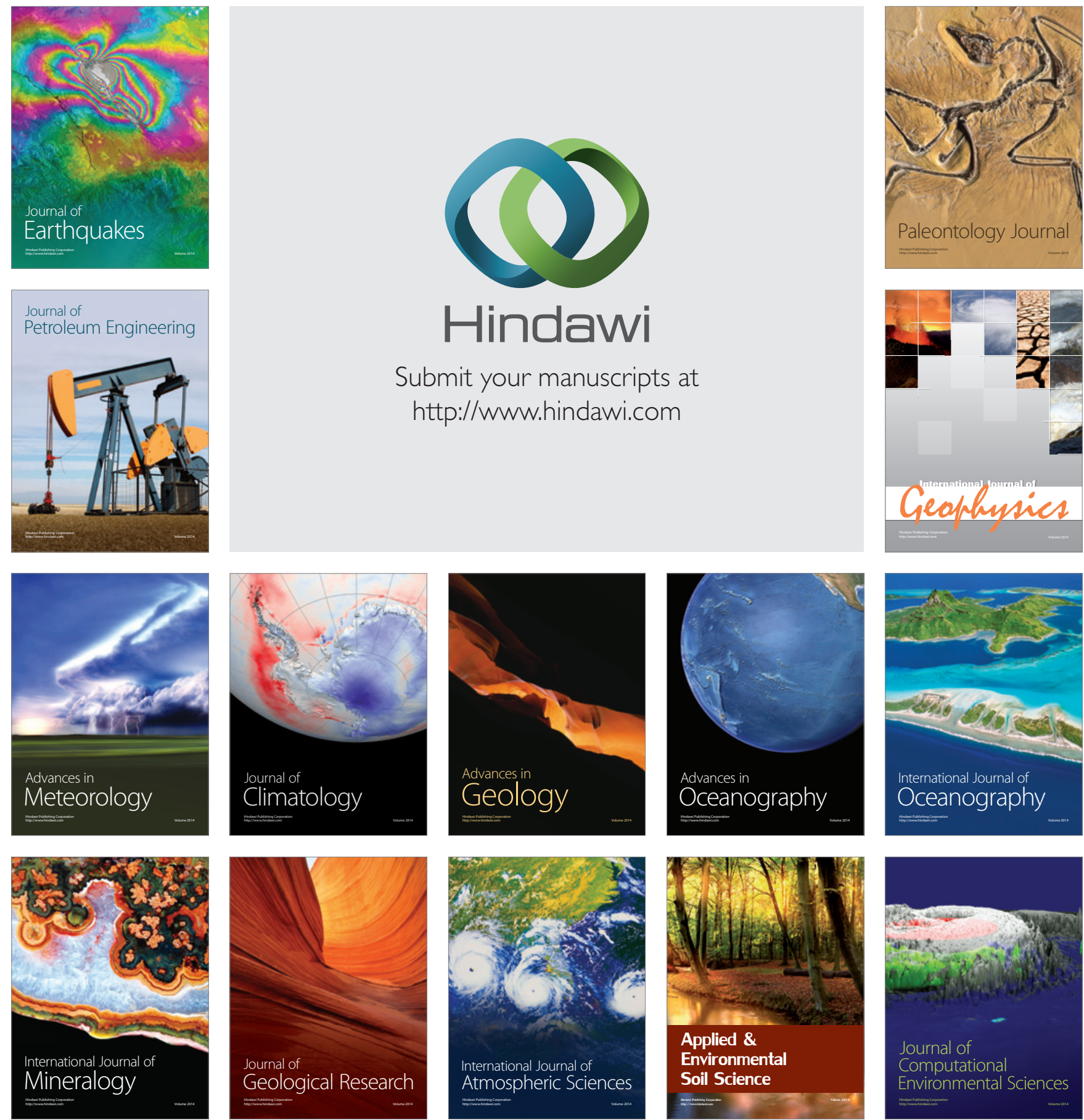